\title{
Slowing the Increase in the Population Dose Resulting from CT Scans
}

\author{
D. J. Brenner
}

Center for Radiological Research, Columbia University Medical Center, New York, New York 10032

Brenner, D. J. Slowing the Increase in the Population Dose Resulting from CT Scans. Radiat. Res. 174, 809-815 (2010).

The annual number of CT scans in the U.S. is now over 70 million. The concern is that organ doses from CT are typically far larger than those from conventional X-ray examinations, and there is epidemiological evidence of a small but significant increased cancer risk at typical CT doses. Because CT is a superb diagnostic tool and because individual CT risks are small, when a CT scan is clinically indicated, the CT benefit/risk balance is by far in the patient's favor. Nevertheless, CT should operate under the ALARA (As Low As Reasonably Achievable) principle, and opportunities exist to reduce the significant population dose associated with CT without compromising patient care. The first opportunity is to reduce the dose per scan, and improved technology has much potential here. The second opportunity is selective replacement of CT with other modalities, such as for many head and spinal examinations (with MRI), and for diagnosing appendicitis (selective use of ultrasound + CT). Finally, a fraction of CT scans could be avoided entirely, as indicated by CT decision rules: Clinical decision rules for $\mathrm{CT}$ use represent a powerful approach for slowing down the increase in CT use, because they have the potential to overcome some of the major factors that result in some CT scans being undertaken when they are potentially not clinically helpful. In the U.S. and potentially elsewhere, legislative approaches are a possible option, to improve quality control and reduce clinically unneeded CT use, and it is also possible that upcoming changes in heath care economics will tend to slow the increase in such CT use. ๑ 2010 by Radiation Research Society

\section{INTRODUCTION}

It is estimated that more than 69 million CT scans were performed in the U.S. in 2007 (1). Such use is a reflection of the fact that $\mathrm{CT}$ is such an accurate, rapid and convenient diagnostic tool. At the same time, at typical organ doses relevant to most CT use [5 to $100 \mathrm{mSv}(2)]$, the X-ray exposure represents a small but well-established cancer risk. Clearly the goal is to balance these two observations to provide the maximum benefit/risk balance both on an individual and, crucially, on a population basis.

\footnotetext{
${ }^{1}$ Address for correspondence: Center for Radiological Research, Columbia University Medical Center, 630 West 168th Street, New York, NY 10032; e-mail: djb3@columbia.edu.
}

\section{CT USE}

While CT use is most frequent in Japan, the U.S. and Australia (3), the rates of increase of CT use are quite similar in many other countries. For example, over the past quarter century, CT use has risen about 12 -fold in the UK and more than 20 -fold in the U.S. $(1,4,5)$. The current annual use is estimated to be more than 3 million per year in the UK and more than 70 million per year in the U.S. In the U.S., about 5 to $10 \%$ of all CT scans are on children $(6,7)$.

The various CT-based health screening applications (lung cancer screening, virtual colonoscopy, cardiac screening) are not yet quite ready for mass use, but some may be soon, resulting in an expected further jump in CT use $(2,8-11)$.

\section{Multiple CT Scans}

While approximately 70 million CT scans are performed annually in the U.S., the number of people receiving these scans is likely to be closer to 30 million because individuals who have a $\mathrm{CT}$ scan for a particular medical issue have, on average, between two and three CT scans $(7,12)$.

In terms of the number of CT scans that people receive in the long term, Sodickson et al. (13) surveyed 31,000 individuals who had CT scans in 2007 and traced the number of $\mathrm{CT}$ scans each had received in the previous 20 years. The average number of CT scans was six, with $1 \%$ of the individuals receiving at least $38 \mathrm{CT}$ scans. The maximum number of CT scans was 132 .

\section{POTENTIAL RISKS ASSOCIATED WITH CT SCANS}

Concerns arise because a CT scan results in organ doses that are much larger than those from conventional radiological procedures such as chest $\mathrm{X}$ rays. The typical maximum organ dose for a set (one or more) of CT scans for a given ailment ranges from about 5 to $100 \mathrm{mSv}$ (2); this wide dose range is due to variability in the number of scans, the type of scans, machine and machine-setting variability, and age/size variability (2, $6)$. In this dose range $(5-100 \mathrm{mSv})$, there is epidemiological evidence $(14,15)$ of a small but statistically 
TABLE 1

Solid Cancers (15) in A-bomb Survivors (19581994), Limited to Individuals Exposed to Doses Comparable to Organ Doses Associated with Typical CT Exposure Series ${ }^{a}$

Study population $(5-100 \mathrm{mSv})$

Total solid cancers observed

Estimated radiation-related excess cancers

Attributable fraction ${ }^{c}$

30,524

4,119

$77^{b}$

$1.8 \%$

${ }^{a}$ Note that the A-bomb survivors were exposed to an essentially whole-body dose, as opposed to the highly localized exposure associated with CT scans. This difference is, of course, taken into account in the CT risk estimation process $(2,4)$.

${ }^{b}$ Statistically significant increase, $P=0.05$, one-sided test.

${ }^{c}$ Proportion of solid cancers in this low-dose subcohort of A-bomb survivors that is attributable to the radiation exposure.

significant increase in cancer risk among A-bomb survivors (see, for example, Table 1). Indeed, as early as 2002, the International Commission on Radiological Protection (ICRP) commented that: "The absorbed dose to tissue from CT can often approach or exceed the levels known to increase the probability of cancer" (16).

It is important to note here that, while there is considerable uncertainty about the most appropriate way to extrapolate radiation risks to doses below those that are epidemiologically accessible, the organ doses associated with CT are in a range that can be (and has been) studied epidemiologically $(14,15)$. Thus the debate, for example, about the validity of the linear no-threshold (LNT) risk extrapolation, while pertinent to possible risks associated with conventional radiological examinations, is much less relevant for CT.

The individual risks associated with doses in the CT range are small. For example, for the subgroup of Abomb survivors exposed in the dose range from 5 to $100 \mathrm{mSv}$, the estimated attributable fraction (proportion of solid cancers attributable to the radiation exposure) is only $1.8 \%(14,15)$. CT use concerns thus largely relate to population risk and public health (a small risk multiplied by a large population subject to this risk) rather than to individual risks.

The epidemiological data in Table 1 are averaged over a population of all ages. However, there is a strong dependence of radiation risk on age at exposure, with compelling evidence that children are considerably more sensitive than adults to radiation-induced cancer (17). While early CT scanners were rarely used for children because they were comparatively slow and thus required anesthesia, pediatric CT use is now increasing rapidly (18). Consequently there is considerable concern about the long-term consequences of pediatric CT, and a retrospective study of mortality and cancer incidence in over 200,000 young people scanned with CT in the UK prior to 2002 has recently been initiated (19).

\section{APPROACHES TO REDUCING THE COLLECTIVE DOSE FROM CT}

There are three ways to reduce or at least stem the increase in the collective dose resulting from CT use without compromising patient care. These are:

1. reducing the dose per CT scan,

2. replacing $\mathrm{CT}$ scans with other imaging modalities, where possible, and

3. minimizing the number of CT scans given that are not medically necessary.

\section{Reducing the Dose per CT Scan}

There have been considerable technological advances in reducing the dose per scan (20), which is especially important for children. This can be done either by manually adjusting the mAs settings for individuals of different sizes (21) or, as pioneered by Kalender and colleagues (22), by automated current modulation. These automated techniques are now built in to most of the newer CT scanners, though how much they are being used is less certain (23).

There is some evidence that doses per CT scan are decreasing: In a comparison of the settings used by members of the Society of Pediatric Radiology (SPR), Arch and Frush (24) found that mAs settings decreased significantly between 2001 and 2006 for pediatric CT; they suggested that these changes may well be due to increased awareness of radiation risks. This having been said, members of the SPR are probably among the most aware of radiation issues of any physician group, so this decrease may not necessarily be generalizable.

\section{Replacing CT Scans with Other Imaging Modalities}

In appropriate situations, the two alternatives are MRI and ultrasound. The selective application of ultrasound for assessing pediatric appendicitis is discussed below. There are a variety of scenarios where MRI can replace CT without loss of efficacy (25-31), common examples being imaging of the brain (26) and the lumbar spine (27). A recent study (29) suggested that about $27 \%$ of CT scans in young patients could, according to the European Community referral criteria (32), be replaced by MRI examinations. In practice, of course, there are currently not enough MRI machines in the U.S. to perform an addition annual $0.27 \times 70$ million $(\approx 20$ million) MRI scans; in addition, MRI scans are typically almost twice as expensive as CT scans.

\section{Potential for Reducing or Slowing the Increase in CT Use}

The issue here is whether there are a significant number of CT scans being performed that are clinically unhelpful and that could thus potentially be eliminated 
TABLE 2

Retrospective Comparison (33) of Six Clinical Decision Rules for CT Scanning of Mild Traumatic Brain Injury in 8,000 Patients

\begin{tabular}{lcc}
\hline Decision rule & $\begin{array}{c}\text { Sensitivity for surgical } \\
\text { hematoma }\end{array}$ & $\begin{array}{c}\text { Percentage of CT scans } \\
\text { that would be avoided }\end{array}$ \\
\hline Canadian $^{a}$ & 0.99 & 44 \\
NCWFNS $^{b}$ & 0.99 & 44 \\
New Orleans $^{c}$ & 0.99 & 31 \\
Nexus-II $^{d}$ & 1.00 & 44 \\
NICE $^{e}$ & 0.98 & 39 \\
Scandinavian $^{f}$ & 0.99 & 50
\end{tabular}

Note. All the decision rules have high sensitivity, i.e., correct classification of lesion requiring surgical intervention, and all would reduce $\mathrm{CT}$ use by approximately one half.

$a$ The Canadian CT Head Rule.

${ }^{b}$ The Neurotraumatology Committee of the World Federation of Neurosurgical Societies instrument.

${ }^{c}$ The New Orleans Criteria.

${ }^{d}$ The National Emergency X-Radiography Utilization Study-II instrument.

${ }^{e}$ The National Institute of Clinical Excellence strategy.

${ }^{f}$ The Scandinavian Neurotrauma Committee guideline.

without compromising patient care. This can be assessed through the potential efficacy of clinical decision rules. A clinical decision rule is a tool designed to help clinicians make diagnostic and therapeutic decisions - in this case providing sets of specific indications for which a CT scan is recommended. There have been many retrospective studies of the proportion of $\mathrm{CT}$ scans that could have been avoided if a high-sensitivity clinical decision rule for $\mathrm{CT}$ scanning had been applied; by high sensitivity, we mean a decision rule that would not exclude any clinically useful scans. An example is shown in Table 2 for a variety of CT decision rules for patients presenting with mild closed traumatic brain injury (33, 34 ). In this case, by following the decision rules, the number of CT scans could be reduced by 30 to $50 \%$ without compromising patient care.

As discussed below, similar reductions in $\mathrm{CT}$ use have been estimated for other diagnostic end points $(35,36)$. Common situations where there is considerable scope for reduction in CT use include $(37,38) \mathrm{CT}$ for renal colic (39), CT for minor head injury (40), CT for abdominal pain (41), CT for abdominal and chest trauma (42), CT angiography for pulmonary embolus (43), and CT of the lumbar spine (27).

\section{Practical Approaches to Slowing the Increase in CT Use}

Whatever the actual proportion of CT scans that could potentially be eliminated, reducing or even slowing down the increase in CT use will be an extremely hard task for a variety of reasons. In particular the issues of patient throughput, legal issues, economic issues, and pressures from patients and parents to have the best available treatment all tend to mitigate against slowing or decreasing CT use.
This having been said, there clearly are approaches to reducing CT use that are practical and that will not compromise patient care. An example is in the assessment of appendicitis - of particular importance because it is typically a young person's disease. Until a few years ago, clinical observation and/or ultrasound were the standard tools to confirm the diagnosis prior to surgery. Currently, CT is the gold standard for diagnosing appendicitis, and in many institutions all patients get a CT scan prior to an appendectomy. An alternative approach (Fig. 1B) is first to use ultrasound; if the ultrasound is positive, then an appendectomy follows, while if it is negative or equivocal, then a CT is given. As shown by Garcia Peña (36), this can reduce CT use by about $30 \%$. More complex schemes (Fig. 1C) are feasible with correspondingly greater potential reductions in CT use. For example, the Alvarado scoring system (44), which is based purely on history, clinical examination and routine laboratory tests, is a highly sensitive and specific tool for identifying high-risk patients who can go to surgery without imaging as well as low-risk patients who can appropriately undergo just observation, again without imaging. Intermediate-risk patients would be imaged by the sequential ultrasound/ CT approach described above. This approach (Fig. 1C) has the potential to cut the number of CT scans used to diagnose appendicitis by more than a factor of two (36).

\section{Utility of Clinical Decision Rules for CT}

These alternate schemes for diagnosing appendicitis represent examples of the potential use of clinical decision rules. The American College of Radiology (ACR), the Royal College of Radiologists, and the European Commission have all published some decision rules (also called appropriateness criteria) for the appropriate use of CT $(32,45,46)$, as have various bodies associated with specific subspecialties $(33,47)$.

As an example of their application, Hadley et al. (35) recently published a retrospective study of the ACR appropriateness criteria (decision rules) for trauma. They studied 200 trauma patients who had some radiation imaging, the imaging decisions having been made without the use of decision rules. A total of 169 had CT scans, for a total of 660 scans. Had the ACR Appropriateness Criteria been applied, $44 \%$ of the CT scans would not have been carried out. None of the major injuries would have been excluded from CT imaging, though 11 minor injuries, none of which required followup, would have been excluded from $\mathrm{CT}$ imaging.

It is also pertinent here to mention the financial implications. In the retrospective study of appropriateness criteria for trauma discussed above (35), the estimated cost of the CT scans actually performed was a little over $\$ 0.8$ million. Had the ACR appropriateness criteria been applied, as well as a $44 \%$ decrease in 

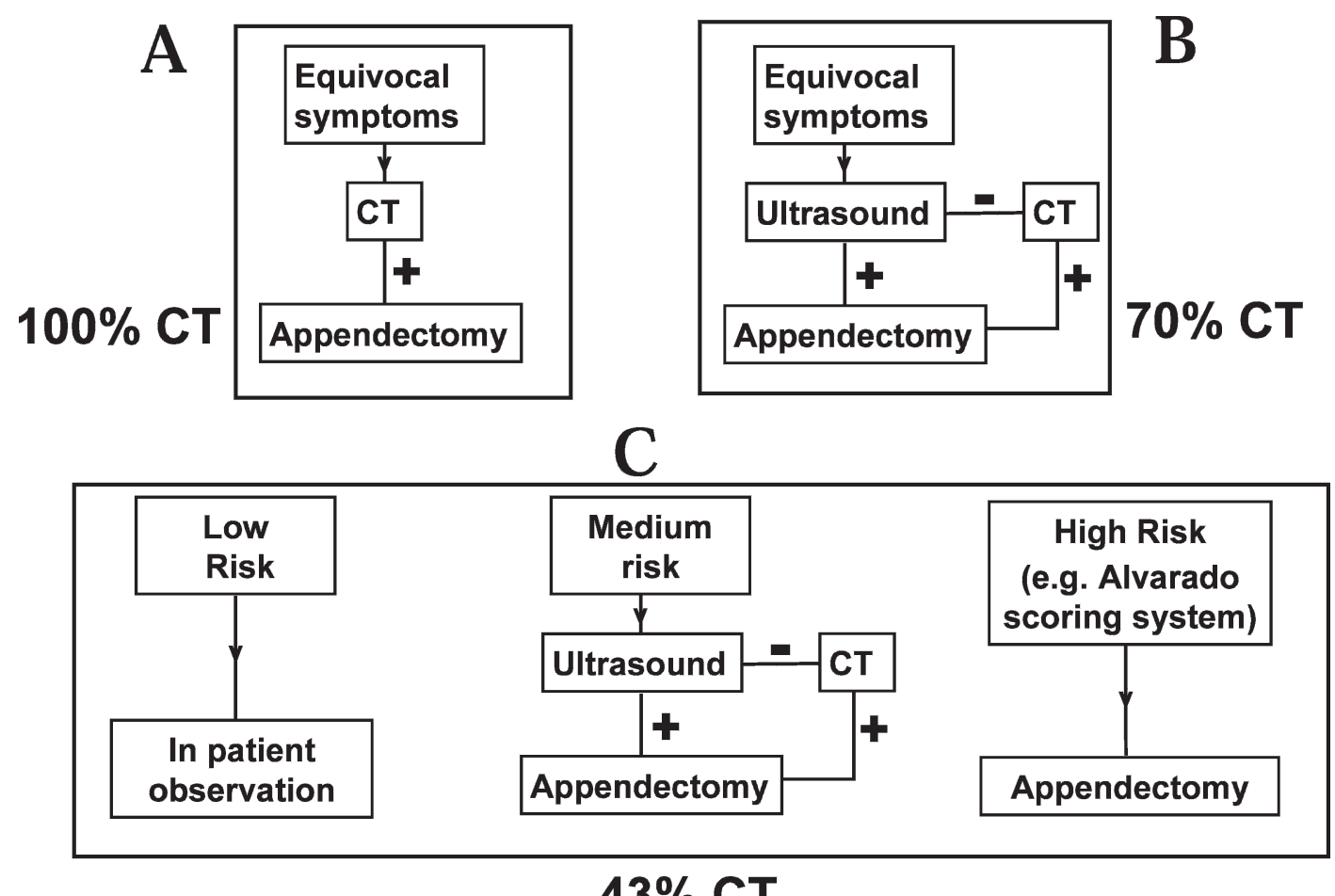

$43 \%$ CT

FIG. 1. Approaches to diagnosis of appendicitis (36). Panel A: All individuals with symptoms are given a CT. Panel B: All individuals with equivocal symptoms are first examined with ultrasound: If the ultrasound is positive, the patient proceeds to surgery; if the ultrasound is negative, a CT is given; a $30 \%$ reduction in CT use is achievable with this approach. Panel C: A more complex decision rule: High-risk patients, as determined without imaging (44), go directly to surgery, low-risk patients have in-patient observation, and intermediaterisk patients are treated as in panel B; a $57 \%$ reduction in CT use is achievable with this approach.

collective dose, there would have been an estimated $38 \%$ decrease in cost.

\section{Application of Clinical Decision Rules for CT}

It is argued here that clinical decision rules for CT use represent a potentially powerful tool for slowing down the increase in CT use, because they have the potential to "trump" some, though not all, of the major factors that result in CT scans being undertaken when they are not strictly medically necessary.

Of course, the factors that feed into a decision rule are complex, the data often incomplete, and the rules need to be adjusted constantly to take into account new evidence. However, in the examples given here, and in other cases reported in the literature, clinical decision rules would be effective in reducing the number of CT scans (as well as the cost) without adversely effecting diagnostic efficacy.

In fact, in the example discussed above (35), clinical rules were not applied, and this situation is often the norm (48). For example, the results of a recent study (49) of awareness of and use of the Canadian CT Head Decision Rule (awareness: 66\% in the UK, $31 \%$ in the U.S.; use of rule: $21 \%$ in the UK, $12 \%$ in the U.S.) suggest that there is considerable room for improvement in $\mathrm{CT}$ decision rule awareness and use.
Two practical approaches toward increased use of CT decision rules are either to build them into a managed care preauthorization program (50) or to incorporate them into a computerized radiology order entry system (51). Both these types of approaches, much considered for purely economic reasons $(52,53)$, have proved successful in curbing the growth of CT use:

- In the case of the managed-care preauthorization approach, in the Israeli experience (50), before preauthorization was required, CT use rates were increasing by about $20 \%$ per year; after preauthorization (by board-certified radiologists) was implemented, CT use rates decreased by about $10 \%$ per year between 2000 and 2003. In contrast, however, in another setting, a CT preauthorization system did not apparently decrease CT use (54).

- In the case of a computerized radiology order entry system, one of which is in place at Massachusetts General Hospital (51), the physician inputs into the system a set of signs/symptoms, followed by the requested imaging test; the system responds with a quantitative assessment of the utility of the requested imaging test, together with a list of alternate procedures to consider, again with utility assessments; the physician is then free to proceed with or change the imaging request. At Massachusetts General 
Hospital, before these decision support rules were in place, outpatient $\mathrm{CT}$ volume was increasing by $\sim 13 \%$ per year; since they were put in place, in 2005, CT use has stayed roughly constant (51).

\section{CONCLUSIONS}

The annual number of CT scans in the U.S. is now over 70 million. The concern is that radiation doses from CT are typically 100 times those from conventional X-ray examinations such as chest $\mathrm{X}$ rays or mammograms, and there is direct epidemiological evidence of a small but significant increased cancer risk at CT doses. Because CT is a superb diagnostic tool and because individual $\mathrm{CT}$ risks are small, when a CT scan is clinically indicated, the CT benefit/risk balance is by far in the patient's favor.

However, there is general acceptance that a significant fraction of all CT scans could be avoided altogether or replaced with a different diagnostic tool. So, while CT risks are small, a small risk multiplied by many millions of scans may translate into a public health concern some years in the future, particularly from pediatric CT.

In conclusion, there are three major issues that are commonly raised with regard to $\mathrm{CT}$ use:

1. "Increased cancer risks at very low doses are very uncertain and depend on extrapolating risks from $A$ bomb survivors who were exposed to high doses." At very low radiation doses, typical of most radiological examinations, it is indeed uncertain whether cancer risks are increased. However, at the higher doses corresponding to a typical CT series (5 to $100 \mathrm{mSv}$ ), there are direct epidemiological data from $\sim 30,000 \mathrm{~A}$ bomb survivors who were on the peripheries of the two cities and who were exposed in this low-dose range $(14,15)$. This low-dose subpopulation has been followed for more than 50 years and shows a small but statistically significant increased cancer risk. Thus, in the context of CT, we do not need to extrapolate from higher doses, with all the attendant uncertainties which that involves.

2. "Many who need CT scans will not have them because of publicized cancer risk estimates." The evidence does not support this: for example, in a recently published study (55), when parents were informed about CT risks, their willingness to have their child undergo a CT did not change significantly, although they became more willing to consider other imaging options, if equally effective; no CTs were cancelled or deferred after receiving risk information. Indeed, it seems the case that ongoing dialogues on these issues among health care professionals (24), with industry (56), and with the public (57) are practical drivers toward reducing $\mathrm{CT}$ use and $\mathrm{CT}$ doses without compromising patient care.
3. "It will be very difficult to reduce CT use." This is true. Although most prescribed CT scans are medically informative, with a highly favorable benefit/risk balance, there are often very real pressures from the medical system, from the medico-economic system, from the medico-legal system, and from the public (58) to use CT when it is not necessarily medically informative or when alternatives exist. Whether legislative approaches are needed or are appropriate in this context is an issue under much current debate $(59,60)$. On the other hand, in the U.S. and potentially elsewhere, it is possible that upcoming changes in heath care economics $(52,53,61)$ will themselves tend to slow the increase in CT use.

\section{ACKNOWLEDGMENTS}

The advice of Drs. Eric Hall, Walter Burden, Dale Preston, Kyoji Furukawa, Elaine Ron, Fred Mettler and Carl Elliston is gratefully acknowledged. This work was supported by grants from the National Cancer Institute (R01 CA088974) and the National Institute of Allergy and Infectious Diseases (U19 AI67773).

Received: April 18, 2009; accepted: July 16, 2009; published online: August 23, 2010

\section{REFERENCES}

1. CT Market Summary Report. International Marketing Ventures, Des Plaines, IL, 2008. [Available online at http://www.imvinfo.com]

2. E. J. Hall and D. J. Brenner, Cancer risks from diagnostic radiology. Br. J. Radiol. 81, 362-378 (2008).

3. Organisation for Economic Co-operation and Development, OECD Health Data 2008: Statistics and Indicators for 30 Countries. OECD, Paris, 2008. [Available online at http://stats. oecd.org/Index.aspx?DatasetCode $=$ health $]$

4. Department of Health, Department of Health Hospital Activity Statistics: Imaging and Radiodiagnostics Data files. [Available online at http://www.performance.doh.gov.uk/hospitalactivity/ data requests/imaging and radiodiagnostics.htm 2008]

5. D. J. Brenner and E. J. Hall, Computed tomography-an increasing source of radiation exposure. N. Engl. J. Med. 357, 2277-2284 (2007).

6. S. Stern, R. Kaczmarek, D. Spelic and O. Suleiman, Nationwide Evaluation of X-ray Trends (NEXT) 2000-2001 survey of patient radiation exposure from computed tomographic (CT) examinations in the United States. Radiology 221(P), 161 (2001). [Also see www.fda.gov/cdrh/ct/ct-next.ppt]

7. F. A. Mettler, Jr., P. W. Wiest, J. A. Locken and C. A. Kelsey, CT scanning: patterns of use and dose. J. Radiol. Prot. 20, 353 359 (2000).

8. W. C. Black, Computed tomography screening for lung cancer: review of screening principles and update on current status. Cancer 110, 2370-2384 (2007).

9. N. Waugh, C. Black, S. Walker, L. McIntyre, E. Cummins and G. Hillis, The effectiveness and cost-effectiveness of computed tomography screening for coronary artery disease: systematic review. Health Technol. Assess. 10, 1-41 (2006).

10. P. J. Pickhardt and D. H. Kim, CT colonography (virtual colonoscopy): a practical approach for population screening. Radiol. Clin. North Am. 45, 361-375 (2007).

11. C. D. Furtado, D. A. Aguirre, C. B. Sirlin, D. Dang, S. K. Stamato, P. Lee, F. Sani, M. A. Brown, D. L. Levin and G. Casola, Wholebody CT screening: spectrum of findings and recommendations in 1192 patients. Radiology 237, 385-394 (2005). 
12. J. E. Winslow, J. W. Hinshaw, M. J. Hughes, R. C. Williams and W. P. Bozeman, Quantitative assessment of diagnostic radiation doses in adult blunt trauma patients. Ann. Emerg. Med. 52, 93-97 (2008).

13. A. Sodickson, P. F. Baeyens, K. P. Andriole, L. M. Prevedello, R. D. Nawfel, R. Hanson and R. Khorasani, Recurrent CT, cumulative radiation exposure, and associated radiation-induced cancer risks from CT of adults. Radiology 251, 175-184 (2009).

14. D. L. Preston, E. Ron, S. Tokuoka, S. Funamoto, N. Nishi, M. Soda, K. Mabuchi and K. Kodama, Solid cancer incidence in atomic bomb survivors: 1958-1998. Radiat. Res. 168, 1-64 (2007).

15. D. A. Pierce and D. L. Preston, Radiation-related cancer risks at low doses among atomic bomb survivors. Radiat. Res. 154, 178186 (2000).

16. ICRP, Managing Patient Dose in Computed Tomography. ICRP Publication 87, Elsevier Science, Amsterdam, 2002.

17. National Research Council, Committee on the Health Risks from Exposure to Low Levels of Ionizing Radiation, Health Risks from Exposure to Low Levels of Ionizing Radiation-BEIR VII. The National Academies Press, Washington, DC, 2006.

18. J. Broder, L. A. Fordham and D. M. Warshauer, Increasing utilization of computed tomography in the pediatric emergency department, 2000-2006. Emerg. Radiol. 14, 227-232 (2007).

19. M. S. Pearce, J. A. Salotti, K. McHugh, A. W. Craft, E. Ron and L. Parker, Long-term sequelae of radiation exposure due to CT in childhood - study in progress. In 2007 UK Radiological Congress, Manchester, UK, 2007.

20. C. H. McCollough, A. N. Primak, N. Braun, J. Kofler, L. Yu and J. Christner, Strategies for reducing radiation dose in CT. Radiol. Clin. North Am. 47, 27-40 (2009).

21. D. P. Frush, B. Soden, K. S. Frush and C. Lowry, Improved pediatric multidetector body CT using a size-based color-coded format. Am. J. Roentgenol. 178, 721-726 (2002).

22. W. A. Kalender, S. Buchenau, P. Deak, M. Kellermeier, O. Langner, M. van Straten, S. Vollmar and S. Wilharm, Technical approaches to the optimisation of CT. Phys. Med. 24, 71-79 (2008).

23. J. Hausleiter, T. Meyer, F. Hermann, M. Hadamitzky, M. Krebs, T. C. Gerber, C. McCollough, S. Martinoff, A. Kastrati and S. Achenbach, Estimated radiation dose associated with cardiac CT angiography. J. Am. Med. Assoc. 301, 500-507 (2009).

24. M. E. Arch and D. P. Frush, Pediatric body MDCT: a 5-year follow-up survey of scanning parameters used by pediatric radiologists. Am. J. Roentgenol. 191, 611-617 (2008).

25. J. C. Clarke, K. Cranley, B. E. Kelly, K. Bell and P. H. Smith, Provision of MRI can significantly reduce CT collective dose. $\mathrm{Br}$. J. Radiol. 74, 926-931 (2001).

26. M. D. Deck, C. Henschke, B. C. Lee, R. D. Zimmerman, R. A. Hyman, J. Edwards, L. A. Saint Louis, P. T. Cahill, H. Stein and J. P. Whalen, Computed tomography versus magnetic resonance imaging of the brain. A collaborative interinstitutional study. Clin. Imaging 13, 2-15 (1989).

27. D. Malfair and D. P. Beall, Imaging the degenerative diseases of the lumbar spine. Magn. Reson. Imaging Clin. N. Am. 15, 221238 (2007).

28. R. C. Semelka, D. M. Armao, J. J. Elias and W. Huda, Imaging strategies to reduce the risk of radiation in CT studies, including selective substitution with MRI. J. Magn. Reson. Imaging 25, 900-909 (2007).

29. H. Oikarinen, S. Merilainen, E. Paakko, A. Karttunen, M. T. Nieminen and $\mathrm{O}$. Tervonen, Unjustified CT examinations in young patients. Eur. Radiol. 19, 1161-1165 (2009).

30. M. F. Lin and V. Narra, Developing role of magnetic resonance imaging in Crohn's disease. Curr. Opin. Gastroenterol. 24, 135140 (2008).

31. J. Ward, A. G. Chalmers, A. J. Guthrie, M. Larvin and P. J. Robinson, T2-weighted and dynamic enhanced MRI in acute pancreatitis: comparison with contrast enhanced CT. Clin. Radiol. 52, 109-114 (1997).
32. European Commission, Radiation Protection 118: Referral Guidelines for Imaging. Office for Official Publications of the European Union, Luxembourg, 2001. [Available online at http://ec.europa.eu/energy/ nuclear/radioprotection/publication/doc/118 en.pdf]

33. S. C. Stein, A. Fabbri, F. Servadei and H. A. Glick, A critical comparison of clinical decision instruments for computed tomographic scanning in mild closed traumatic brain injury in adolescents and adults. Ann. Emerg. Med. 53, 180-188 (2009).

34. M. Smits, D. W. Dippel, G. G. de Haan, H. M. Dekker, P. E. Vos, D. R. Kool, P. J. Nederkoorn, P. A. Hofman, A. Twijnstra and M. G. Hunink, External validation of the Canadian CT Head Rule and the New Orleans Criteria for CT scanning in patients with minor head injury. J. Am. Med. Assoc. 294, 1519-1525 (2005).

35. J. L. Hadley, J. Agola and P. Wong, Potential impact of the American College of Radiology appropriateness criteria on CT for trauma. Am. J. Roentgenol. 186, 937-942 (2006).

36. B. M. Garcia Peña, E. F. Cook and K. D. Mandl, Selective imaging strategies for the diagnosis of appendicitis in children. Pediatrics 113, 24-28 (2004).

37. D. Eagles, I. G. Stiell, C. M. Clement, J. Brehaut, A. M. Kelly, S. Mason, A. Kellermann and J. J. Perry, International survey of emergency physicians' priorities for clinical decision rules. Acad. Emerg. Med. 15, 177-182 (2008).

38. M. H. Reed, Imaging utilization commentary: a radiology perspective. Pediatr. Radiol. 38 (Suppl. 4), S660-S663 (2008).

39. J. Broder, J. Bowen, J. Lohr, A. Babcock and J. Yoon, Cumulative CT exposures in emergency department patients evaluated for suspected renal colic. J. Emerg. Med. 33, 161-168 (2007).

40. T. P. Klassen, M. H. Reed, I. G. Stiell, C. Nijssen-Jordan, M. Tenenbein, G. Joubert, A. Jarvis, G. Baldwin, D. St-Vil and M. Colbourne, Variation in utilization of computed tomography scanning for the investigation of minor head trauma in children: a Canadian experience. Acad. Emerg. Med. 7, 739-744 (2000).

41. D. S. Smink, J. A. Finkelstein, B. M. Garcia Pena, M. W. Shannon, G. A. Taylor and S. J. Fishman, Diagnosis of acute appendicitis in children using a clinical practice guideline. $J$. Pediatr. Surg. 39, 458-463 (2004).

42. A. Jindal, G. C. Velmahos and R. Rofougaran, Computed tomography for evaluation of mild to moderate pediatric trauma: are we overusing it? World J. Surg. 26, 13-16 (2002).

43. P. W. Abcarian, J. D. Sweet, J. T. Watabe and H. C. Yoon, Role of a quantitative D-dimer assay in determining the need for CT angiography of acute pulmonary embolism. AJR Am. J. Roentgenol. 182, 1377-1381 (2004).

44. R. McKay and J. Shepherd, The use of the clinical scoring system by Alvarado in the decision to perform computed tomography for acute appendicitis in the ED. Am. J. Emerg. Med. 25, 489-493 (2007).

45. E. S. Amis, Jr., P. F. Butler, K. E. Applegate, S. B. Birnbaum, L. F. Brateman, J. M. Hevezi, F. A. Mettler, R. L. Morin, M. J. Pentecost and R. K. Zeman, American College of Radiology white paper on radiation dose in medicine. J. Am. Coll. Radiol. 4, 272-284 (2007).

46. Making the Best Use of a Department of Radiology: Guidelines for Doctors, 5th ed. Royal College of Radiologists, London, 2003.

47. M. K. Ghanta, L. M. Smith, R. S. Polin, A. B. Marr and W. V. Spires, An analysis of Eastern Association for the Surgery of Trauma practice guidelines for cervical spine evaluation in a series of patients with multiple imaging techniques. Am. Surg. 68 , 563-567; discussion 567-568 (2002).

48. A. B. Bautista, A. Burgos, B. J. Nickel, J. J. Yoon, A. A. Tilara and J. K. Amorosa, Do clinicians use the American College of Radiology Appropriateness criteria in the management of their patients? Am. J. Roentgenol. 192, 1581-1585 (2009).

49. D. Eagles, I. G. Stiell, C. M. Clement, J. Brehaut, M. Taljaard, A. M. Kelly, S. Mason, A. Kellermann and J. J. Perry, International survey of emergency physicians' awareness and use of the Canadian Cervical-Spine Rule and the Canadian Computed Tomography Head Rule. Acad. Emerg. Med. 15, 1256-1261 (2008). 
50. A. Blachar, S. Tal, A. Mandel, I. Novikov, G. Polliack, J. Sosna, Y. Freedman, L. Copel and J. Shemer, Preauthorization of CT and MRI examinations: assessment of a managed care preauthorization program based on the ACR Appropriateness Criteria and the Royal College of Radiology guidelines. J. Am. Coll. Radiol. 3, 851-859 (2006).

51. C. L. Sistrom, P. A. Dang, J. B. Weilburg, K. J. Dreyer, D. I. Rosenthal and J. H. Thrall, Effect of computerized order entry with integrated decision support on the growth of outpatient procedure volumes: seven-year time series analysis. Radiology 251, 147-155 (2009).

52. R. C. Hendel, Utilization management of cardiovascular imaging pre-certification and appropriateness. JACC Cardiovasc. Imaging 1, 241-248 (2008).

53. J. M. Mitchell and R. R. Lagalia, Controlling the escalating use of advanced imaging: the role of radiology benefit management programs. Med. Care Res. Rev. 66, 339-351 (2009).

54. P. B. Smulowitz, L. Ngo and S. K. Epstein, The effect of a CT and MR preauthorization program on ED utilization. Am. J. Emerg. Med. 27, 328-332 (2009).
55. D. B. Larson, S. B. Rader, H. P. Forman and L. Z. Fenton, Informing parents about $\mathrm{CT}$ radiation exposure in children: it's OK to tell them. Am. J. Roentgenol. 189, 271-275 (2007).

56. O. W. Linton and F. A. Mettler, Jr., National conference on dose reduction in CT, with an emphasis on pediatric patients. Am. J. Roentgenol. 181, 321-329 (2003).

57. D. I. Bulas, M. J. Goske, K. E. Applegate and B. P. Wood, Image gently: why we should talk to parents about CT in children. Am. J. Roentgenol. 192, 1176-1178 (2009).

58. L. M. Schwartz, S. Woloshin, F. J. Fowler, Jr. and H. G. Welch, Enthusiasm for cancer screening in the United States. J. Am. Med. Assoc. 291, 71-78 (2004).

59. D. J. Brenner and H. Hricak, Radiation exposure from medical imaging: Time to regulate? J. Am. Med. Assoc. 304, 208-209 (2010).

60. R. Smith-Bindman, Is computed tomography safe? N. Engl. J. Med. 363, 1-4 (2010).

61. U.S. Senate Finance Committee, Transforming the health care delivery system: Proposals to improve patient care and reduce health care costs. Washington, DC, 2009. 